\title{
LA CIUDAD Y LAS RELACIONES MERCANTILES EN EL NACIMIENTO DE LA NOVELA COSTARRICENSE
}

\author{
POR \\ ALVARO QUESADA SOTO \\ Universidad de Costa Rica
}

La mayer parte de los críticos e historiadores de la literatura costarricense coincide en considerar a Joaquín García Monge (1881-1958) y a Jenaro Cardona (1863-1930) como des autores fundamentales para la consolidación del género novelístico en este país. Abelardo Bonilla, en su prestigiosa Historia de la literatura costarricense, afirma: «El creador de la novela costarricense, tanto en el fondo como en la forma, es Joaquín García Monge» '. Sobre la novela Hijas del campo (1900), de este autor, sostiene Bonilla lo siguiente: «E1 autor penetra aquí en el ambiente de la ciudad y en la crítica de una sociedad enferma. El campo está presente..., pero es la ciudad y la estructura social lo que priva como tema y lo que lleva a los amantes al desastre moral y material» ${ }^{2}$.

Con respecto a Cardona, dice Bonilla: «Jenaro Cardona cierra el ciclo del primer realismo costarricense y es el novelista de mayores capacidades en el género» ${ }^{3}$. Sobre la primera novela de Cardona, pondera el mismo crítico: «El primo, publicada en 1905, es el primer intento novelístico de gran aliento que se produce en Costa Rica (...) El primo es ya una novela de la ciudad. El San losé de comienzos de siglo aparece en todos sus aspectos costumbristas y en los vicios de una sociedad que ha abandonado el patriarcalismo y se inicia en la nueva era burguesa, en que la fortuna es el factor esencial» ${ }^{4}$.

\footnotetext{
1. Abelardo Bonilla, Historia de la literatura costarricense (San José: Editorial Costa Rica, 1967), p. 115.

${ }^{2}$ Ibid., p. 117.

3 Ibid., p. 143.

${ }^{4}$ Ibid., pp. 143-144.
} 
Es nuestra intención, en este trabajo, investigar -mediante el análisis de Hijas del campo y El primo- algo que sugerían ya las apreciaciones de Bonilla: cómo el nacimiento de la novela costarricense está íntimamente ligado a la aparición del tema urbano y del crecimiento de las relaciones mercantiles. La imagen de San José aparecen en estas dos novelas, ya no como simple telón de fondo sobre el cual se dibujan anécdotas costumbristas, pintorescas, nostálgicas o divertidas; el espacio urbano surge aquí como campo de fuerzas sociales, cuyas líneas apresan, constriñen y degradan a los personajes. La introducción del tema urbano está también ligada a una imagen dialéctica, ambivalente y degradada de la vida social, en donde las viejas relaciones y concepciones patriarcales son sustituidas por nuevas relaciones y prácticas mercantiles burguesas.

Algunos teóricos europeos de la novela habían señalado ya precisamente la concepción ambivalente, la valoración contradictoria de la realidad social y de las relaciones humanas, como la característica fundamental de ese género literario. Lucien Goldmann estableció una homología entre la estructura de la novela y la estructura de la sociedad burguesa capitalista, fundada sobre relaciones mercantiles ${ }^{5}$. El carácter ambivalente y contradictorio - «degradado»- de la realidad y de las relaciones entre el hombre y la realidad, característico de la novela como género literario, reproduce, para Goldmann, el carácter contradictorio y ambivalente de la mercancía y las relaciones mercantiles, según el análisis que hizo Marx en sus estudios económico-filosóficos.

Según Marx, la característica principal de la mercancía es que puede ser valorada desde dos aspectos: su "valor de uso», que expresa sus cualidades intrínsecas, y su capacidad para satisfacer, mediante el uso y el consumo, necesidades humanas; y su «valor de cambio»: su capacidad para ser intercambiada por otros productos en el mercado. En el último caso no son sus cualidades intrínsecas particulares las que definen su valor, sino circunstancias ajenas, externas al producto mismo y a los factores humanos concretos que intervienen en su proceso de producción y consumo: circunstancias que expresan su valor en la forma abstracta del dinero, equivalente universal de todas las mercancías.

En las sociedades dominadas por relaciones de producción mercantiles, esa ambivalencia se hace extensiva a todas las actividades humanas. Los hombres y los hechos adquieren un doble valor: su valor esencial humano parece perder realidad y convertirse en mero ideal o aspiración subjetiva; mientras su apariencia objetiva, el valor socio-comercial, aparece como la única y verdadera medida de las relaciones humanas. «En la vida

\footnotetext{
${ }^{5}$ Lucien Goldmann, Pour une sociologie du roman (París: Gallimard, 1970).
} 
económica, que constituye la parte más importante de la vida social moderna -escribe Goldmann-, toda relación auténtica con el aspecto cualitativo de los objetos y los seres tiende a desaparecer, tanto de las relaciones entre los hombres y las cosas como de las relaciones entre los hombres mismos, para ser sustituida por una relación mediatizada y degradada: la relación con los valores de cambio puramente cuantitativos. Los valores de uso, por supuesto, siguen existiendo, e incluso rigen, en última instancia, la vida económica en su conjunto; pero su acción toma un carácter implícito, exactamente como los valores auténticos en el mundo de la novela» ${ }^{6}$.

Julia Kristeva, por su parte, señala cómo diversos autores relacionaron la aparición del texto narrativo novelesco con «la pérdida de la unidad mítica», con la «disolución de la unidad medieval... fundada sobre la economía natural» y con «la aparición de la burguesía en la escena política y económica»?

No deja entonces de ser significativo que en estas dos obras fundadoras de la novela costarricense - Hijas del campo y El primo-, la imagen crítica de una realidad social ambivalente y contradictoria - muy distinta de la univocidad tradicional de los cuentos y cuadros de costumbres de la época-, aparezca relacionada con los temas de la descomposición de las relaciones patriarcales, del poder del dinero, la desposesión del campesino y la degradación socio-moral de la vida y el habitante urbanos. Expresan estas obras el tránsito de la vieja estructura patriarcal-burguesa del siglo xix costarricense, cuando las relaciones patriarcales o paternalistas coexistían en estrecha amalgama con las incipientes relaciones burguesas $^{8}$; a la formación de una nueva estructura mercantil-burguesa.

Hijas del campo, por primera vez en la literatura nacional, intentó ofrecer una imagen global de la vida costarricense, al contraponer los campesinos a la oligarquía cafetalera y al mover ambos grupos en sus

${ }^{6}$ Ibid., p. 38.

7 Julia Kristeva, El texto de la novela (Barcelona: Ed. Lumen, 1981), pp. 19-21.

${ }^{8}$ Véase, sobre este punto, la obra de José Luis Vega Hacia una interpretación del desarrollo costarricense (San José: Ed. Porvenir, 1983) y la de Samuel Stone La dinastía de los conquistadores (San José: EDUCA, 1975). Estas mismas ideas fueron aplicadas por el autor de este trabajo al estudio de otras obras literarias del período en sus artículos " Magdalena": el liberalismo, la oligarquía y el matrimonio», en Escena, año 5, núm. 12, e "Ideología y concepción del mundo en la obra de Manuel de Jesús Jiménez», en Káñina, vol. IX, núm. 1. 
espacios sociales correspondientes: el campo (la hacienda cafetalera) y la ciudad (San José). Por primera vez también aparece en esta novela el tema del campesino pobre, desamparado o desposeído, expulsado de su ámbito natural, cuya subordinación socio-económica lo lleva a la degradación o a la prostitución. El crecimiento de la ciudad como espacio vital va acompañado de la sustitución de los viejos valores y relaciones patriarcales por nuevos valores y relaciones mercantiles; el desarrollo de las relaciones mercantiles lleva a la expropiación del pequeño productor campesino, que, desposeído de medios de producción y subsistencia, se ve obligado a emigrar a la ciudad y vender su fuerza de trabajo para mantenerse.

La novela está claramente dividida en dos partes: la primera parte (capítulos I-XVI) presenta las relaciones entre la oligarquía y el campesino, tomando como espacio vital el campo; la segunda parte (capítulos XVII-XXXV) presenta las nuevas relaciones y las nuevas actitudes que surgen entre esos mismos grupos sociales, en el ámbito del espacio urbano. Ambas partes ofrecen una imagen ambivalente de la realidad: en ambas, las aspiraciones y necesidades naturales y humanas se ven constreñidas y deformadas por las convenciones y exigencias socio-económicas. En los dos casos, la deformación está ligada a las relaciones económicosociales, de dominio, por parte de la oligarquía, y de dependencia, por parte del campesino.

El vicio central, que determina la degradación de las relaciones humanas en Hijas del campo, es la desigualdad y la injusticia, inherentes al sistema de relaciones económico-sociales. Esos factores provocan patrones y hábitos de comportamiento que terminan por imponerse a los personajes, aun en contra de sus principios morales y en contra de su conciencia y voluntad. El resultado es un doble proceso de desarraigo social y degradación moral, que abarca - aunque de distinta manera - tanto al oligarca parasitario, que se convierte en explotador y corruptor, como al campesino desvalido, explotado y degradado. Marx había hecho notar cómo «la clase poseedora y la clase del proletariado representan la misma enajenación humana. Pero la primera de ellas se siente bien en esta deshumanización y se ve confirmada por ella: sabe que esta enajenación es su propio poder, y posee en ella una apariencia de existencia humana; la segunda, en cambio, se siente aniquilada en la enajenación, ve en ella su impotencia y la realidad de una existencia inhumana» ${ }^{9}$.

Hijas del campo muestra este doble proceso de enajenación y deshu-

- Citada en Georg Lukács, Problemas del realismo (México: Fondo de Cultura Económica, 1966), p. 205. El subrayado es del original. 
manización. La desigualdad y la injusticia generan tanto el parasitismo egoista de la oligarquía, que termina por considerar «natural» su «derecho» a disfrutar de la sujeción del campesino, como el proceso de degradación material y moral a que condena al campesino su desvalidez y desamparo. La deshumanización es el común denominador de este doble proceso: él provoca tanto la impunidad moral del oligarca, al que su poder convierte en corruptor más o menos inconsciente, como el desarraigo material y moral del campesino, al que su indefensión económico-social lleva, más o menos inconscientemente, a la corrupción y la prostitución.

El papel de la oligarquía como grupo social, con respecto al campesino, es semejante al de la ciudad, como espacio social, con respecto al campo: ambos - grupo y espacio - representan el peso muerto de lo artificial y parasitario, cuya fuerza tiende a someter toda aspiración natural y humana. Por otra parte, la novela establece una oposición dialéctica -no tajante y unilateral- entre los dos grupos — campesinos y oligarquía - o los dos espacios sociales - rural y urbano-: los primeros no acaparan todas las virtudes ni los segundos todos los vicios; el germen de la corrupción, el desarraigo y la penetración de las relaciones mercantiles aparecía ya latente o incipiente en la vida campesina: las descripciones y acontecimientos de la primera parte anuncian ya lo que habrá de desarrollarse en la segunda.

La primera parte muestra el proceso incipiente de penetración de las relaciones mercantiles en la vida rural, la lenta descomposición o desaparición de las relaciones familiares-patriarcales, hasta terminar con la expu1sión de Piedad y Casilda, convertidas en sirvientas a sueldo, y más tarde de Nieves, convertido en policía urbano y buitre de cuartel. Así, el idilio patriarcal del campesino era ya, desde el inicio de la novela, un idilio precario y amenazado.

Con la partida de Piedad y Casilda, que abandonan sus hogares para iniciarse como sirvientas en San José, se cierra la primera parte de la novela. En el capítulo XVI, cuando Piedad y Casilda se encaminan hacia la. capital, el narrador deja patente las actitudes opuestas de las dos hijas del campo hacia lo que dejan y hacia lo que esperan en la ciudad:

-No creas, niñá, yo no me estaré mucho; jcuándo! agüelito se mutere de sólo pensar — decía Piedad, con un cigarrillo entre los labios.

Su vida cristiana, su amor al hogar, creció en ella sin alteración y por eso acariciaba el pensamiento de regresar muy pronto (...).

- Pues a mí - habló Casilda, la cual sentía resurgir con muchos bríos sus aspiraciones latentes- quizás me guste. Ya sabés cuánto hombrecillo malo hay en la villa... Ahí no hay oficios, sólo ser lavandera y es un trabajo que con nada lo pagan. A mí nadie me dio consejos, 
porque nadie me quiere; falta no les haré... En casa, con lo que ganen mama y Filomena, viven; tienen ahora una boca menos y es la mía ${ }^{10}$.

La segunda parte de la novela comienza cuando inician su «noviciado» urbano las hijas del campo. La vida urbana incuba o desarrolla en los campesinos, trasladados a un ambiente contaminado por costumbres y valores artificiales y desarraigados, debilidades y miserias que en el campo se mantenían en estado latente o embrionario. Por otra parte, en la ciudad se modifican sustancialmente los papeles de la oligarquía y los campesinos. La aristocracia ociosa, que aparecía desubicada y fuera de lugar en el ambiente rural, se encuentra holgada y a gusto en el ambiente urbano. El inmigrante campesino, sumido en el desamparo material y espiritual, segregado de su núcleo familiar y su entorno tradicional, es víctima de un amargo proceso de desarraigo y desmoralización.

Los capítulos de la segunda parte reúnen y relacionan mutuamente, en un repetido contrapunto, una intrincada combinación de descripciones, anécdotas, impresiones y recuerdos de los personajes, para ligar diversos planos y aspectos, lo particular y lo general, el plano psicológico y el plano social. Esta contraposición de puntos de vista y diversos personajes permite reflejar así los múltiples aspectos del proceso de desmoralización y corrupción de los inmigrantes campesinos: paulatina, casi inadvertidamente, la ciudad disuelve los valores patriarcales y deshumaniza el «idilio rústico» de Piedad y Nieves, mientras fomenta en una dirección desviada las «aspiraciones latentes» de Casilda.

Los capítulos XX y XXII describen el aprendizaje urbano de Piedad, el proceso psicológico-social que lleva a la paulatina degradación moral del personaje. En la mostración de este proceso el narrador combina las experiencias de Piedad con el relato de otras historias ominosas de emigrantes campesinas convertidas en sirvientas urbanas, a las que la ciudad prostituye, y que provocan y prefiguran, al mismo tiempo, el porvenir de Piedad. Estas historias se mezclan con el ambiente y las costumbres desarraigadas de la ciudad para ir poco a poco, imperceptiblemente, minando y corrompiendo el sedimento moral y las costumbres campesinas de Piedad:

Y esta narración embobó, por el momento, a Piedad, mas la dejó después en su corazón muchas impresiones y el aguijón de la curiosidad innata, que la llevaba a otros mundos como la palomilla al fuego. A su alrededor, mucho ruido, la algarabía de los chiquillos, los pitazos

${ }^{10}$ Joaquín García Monge, Obras escogidas (San José: EDUCA, 1974), pp. 497 498. En adelante, las citas siguientes se harán según esta edición. Sólo se indicará en el texto el número de página correspondiente. 
Je la máquina, el aire atabacado, el dar vueltas de los caballitos, las rameras sentadas en los corceles de madera, sintiendo un lujurioso placer, aquellos aires de música sensualistas por extremo, que tocaban directamente a los sentidos.

Y Piedad, ya en casa, con el recuerdo de esa degradante diversión de los caballitos, con el de muchas amigas, que por un rato de volteretas, agitación y alegría, entregaban el primor de sus formas, a la turba de gavilanes que las perseguían, acostóse, casi mareada, y ya en el lecho, acordóse de Nieves, mas no como de costumbre, casta y blancamente (p. 512).

El capítulo XXIII introduce una nueva voz en el contrapunto urbano: la de Nieves. La figura de Nieves, al que la adversidad y las hipotecas obligan a abandonar su tierra para ingresar al cuartel, se une a la roz de Piedad, para mostrar una nueva variante en el proceso urbano de desmoralización del inmigrante campesino. Los capítulos XXIV a XXVIII muestran el proceso de degradación urbano de Nieves y Piedad, que transforma y corrompe el «idilio rústico», el amor ingenuo y puro de la antigua pareja campesina.

Nieves, por de pronto, necesitó hacer lo mismo que observaba a diario; irse a casas de mala ley. Perdió su corazón de niño, hízose un malicioso puerco, borró su voluntad y la buena fe que abrigaba, con respecto de su matrimonio con Piedad; olvidó su respeto para con ésta, echóle el brazo y por las noches encaminábase a la Avenida de las Damas... Sentábanse ambos, en uno de los poyos... para entregarse a los besuqueos lujuriosos, a profanaciones increíbles, no del lugar, sino de los recuerdos de las pasadas escenas del terruño (p. 516).

La campesina, medio mes llevaba de no andar con él; había descendido a tanto su perversión, que Nieves ya le era demasiado honesto: se le antojaba todavía muy cándido, muy metido en sus preocupaciones y no le satisfacía (p. 524).

En forma paralela a la historia de Nieves y Piedad se desarrolla, en un nuevo contrapunto, el proceso urbano de seducción y corrupción de Casilda por el señorito Manuel: el contrapunto Nieves-Piedad/CasildaMelico evidencia dos aspectos diferentes del mismo proceso de aprendizaje y degradación.

Hacia otro camino torcía Casilda sus gustos... Casilda no tenía la timidez innata en otras sirvientas, que no tocan un objeto y si se atrevían a mirarlo era por curiosidad instintiva; al contrario, con el desparpajo mayor, mecíase en las poltronas de resortes, y muy a su gusto, como si ahí sentada, en medio de aquel ajuar aristocrático, estuviese la realización de alguno de sus sueños (p. 509). 
La contradicción entre el lujo y el refinamiento ajenos que rodean su vida, por una parte, y su precaria situación social y económica, por otra, fomentan en Casilda «aspiraciones latentes» y ambiciones que sobrepasan sus exiguos medios. La contradicción entre sus pretensiones irrealizables y sus precarias posibilidades para satisfacerlas convierten a Casilda en una mercancía fácilmente accesible a las transacciones erótico-mercantiles del señorito Manuel: él ofrece a la sirvienta el lujo y la independencia a los que ella aspira, y ella paga el precio que se le fija: la prostitución.

- iQué gusto el tuyo! Viviendo en un infierno como el de esta casa, expuesta a que te trapeen criadillas y cocineras, aguantando las malas lunas de mi madre. ¡Ajj! No sería mejor para ti que viviésemos juntitos, en una salita preciosa, en las afueras de San José... (p. 534).

Ella comprendía que viviendo, como hasta ahora, en unión de sus amas, éstas algún día la casarían con un hombre de la clase media, un pintor de brocha gorda, o tal vez con un obrero. Pero... tales gentes le parecían poco... ¿Pensar en un matrimonio con uno de los señoritos encopetados? Esto habría sido un absurdo, porque los tales, a duras penas se casan con las de su círculo. Pero Casilda deseaba ser parte interesante de alguien. Y sus ojos húmedos fijábanse en Melico... (pp. 536-537).

Luego viene la seducción (capítulo XXXIII), más tarde el embarazo y el aborto (capítulo XXXIV), y Casilda se convierte en amante permanente del señorito Manuel. Las reflexiones finales de Melico, en el último capítulo de la novela, dejan a Casilda a las puertas del abandono y en los umbrales de la prostitución.

El monólogo de Melico, con el que se cierra la novela en el capítulo XXXV, pone en evidencia las raíces sociales del doble proceso de alienación y deshumanización, que abarca, aunque de distinta manera, tanto al oligarca parasitario y corruptor como al campesino desposeído y degradado. Los tímidos escrúpulos de conciencia del señorito, su débil sentimiento de culpabilidad por la seducción y la corrupción moral de Casilda, se ven atenuados, y su acción se encuentra justificada, por la autoridad de la costumbre y las convenciones sociales: aunque dice sentirse «casi enfermo», se "consuela» con el hecho de que su acción es «muy practicada en el país»; la «desigualdad social», por otra parte, convierte un posible matrimonio en "un heroísmo», del cual Melico se siente "muy incapaz» (p. 543). Sus tímidos arrestos de sensibilidad no pueden ocultar la hipocresía, el cinismo y la crueldad que esconden sus palabras de justificación:

-No, mejor la abandono: ya queda instalada. Ahora que comercie con sus formas... Yo me he portado bien, poniéndola en condiciones 
de hacer mucho en la carrera (...). Mis compañeros... lo sabrían de seguro y me embromarían delante de mis amigas, señoritas maliciosas que pronto darán en el clavo. Y de éstas pasaría a las señoras, a mis hermanas, a... mi madre... Que se la lleven Paco, Elías, Tijo, el diablo mismo, si es posible, con tal que no se averigüe nada... que la llamen Nueva, le pongan un mote, lo que quieran, pero que no mienten a Melico... ¡no! (pp. 543-544).

Melico justifica así la mezquindad y el egoísmo de su comportamiento, como una actitud «normal» y «necesaria» para mantener el respeto a las tradiciones familiares y a las convenciones sociales establecidas.

De esta manera, en el contrapunto Melico-Casilda de los últimos capítulos, el narrador resume y subraya las raíces y consecuencias sociales que contiene el tema central de la novela, el tema de la emigración del campesino desamparado o desposeído a la ciudad. El desamparo de unos y el poder socio-económico de otros convierte las relaciones entre los hombres en relaciones degradadas y deshumanizadas: convierte a los desposeídos en mercancía, inclinada por su carencia de medios a venderse, y a los poseedores en mercaderes de la miseria humana, que trafican y medran con la indigencia de los desposeídos.

El resultado es un mundo urbano de relaciones inhumanas, contrahechas y deformes, en donde las prácticas sociales - valores de cambiose basan sobre la negación o la perversión de las necesidades y los sentimientos auténticamente humanos. La crueldad y la injusticia parecen actitudes «normales» y «necesarias», mientras las relaciones y sentimientos humanos auténticos y naturales - los valores de uso- parecen inútiles e irreales.

\section{III}

El rasgo principal que asemeja El premio de Jenaro Cardona a Hijas del campo es la ambivalencia. El tema central de esa novela es la lucha entre los valores y prácticas del viejo liberalismo patriarcal costarricense y los valores y prácticas sedicentes del nuevo liberalismo burgués. Cardona recoge también de García Monge el tema de la ciudad: la vida del San José finisecular, con pujos crecientes de pequeña urbe burguesa, funge como representación condensada del avance de los nuevos valores mercantiles y de su influencia en la descomposición y desmoralización de la vida social. Estos aspectos de la novela habían sido registrados ya certeramente por Abelardo Bonilla al hablar de El primo como «tna novela de la ciudad» que describe "una sociedad que ha abandonado el patriarcalismo y se inicia en la nueva era burguesa». 
El enfoque ideológico que da Cardona a estos hechos en su novela difiere, sin embargo, de la posición de García Monge. Los problemas sociales que García Monge había enfocado desde el punto de vista del campesino desposeído, Cardona los enfoca desde el punto de vista de las clases medias y los nuevos ricos del país. Los valores de uso - las necesidades naturales humanas - se identifican aquí con los valores y principios del viejo liberalismo patriarcal, degradados y corrompidos por el nuevo liberalismo burgués mercantilista. Era una posición muy frecuente entre los escritores de la generación de Cardona; Carlos Gagini la había resumido elocuentemente en su obra Don Quijote se va:

Honradez, honor, equidad, patriotismo, compasión, abnegación y nobleza son palabras anticuadas y vacías de sentido en nuestra lengua... Los caballeros de antaño tenían un Dios, una patria y una dama; los mercaderes de hoy no tienen más Dios que el dinero, más patria que el mostrador, ni más dama que la bolsa ${ }^{11}$.

La novela $\mathrm{El}$ primo se estructura sobre dos tramas entrelazadas ${ }^{12}$ que forman, en contrapunto, un reflejo de la descomposición y la desintegración del viejo núcleo familiar patriarcal, producto de la seducción que ejercen sobre sus miembros más jóvenes los nuevos valores mercantiles burgueses. Las dos tramas establecen un nexo entre el proceso de descomposición familiar de la oligarquía urbana y un proceso semejante que se opera en las familias de ricos «gamonales» campesinos.

La trama central expresa el proceso de decadencia de la antigua oligarquía aristocrática venida a menos - el viejo «nido de hidalgos» criollo--, encarnado en la familia Ayala, cuyos exiguos recursos económicos no alcanzan ya a sufragar las apariencias sociales que su posición le exige mantener. Los tres miembros de la familia representan distintas actitudes ante esta situación. Don Clemente Ayala, el padre, es el representante típico del viejo liberalismo paternalista, en el que se mezclan la añoranza por el «orden y el concierto» patriarcales con la fe en el «progreso» liberal. Pero al mismo tiempo el narrador reconoce la incapacidad de las virtudes patriarcales de don Clemente, «todo ingenuidad y confianza», para conservar su patrimonio en los nuevos tiempos «de lucha y positivismo», de «rapiña» y «expoliación»:

$\mathrm{Y}$ es que sobre las cabezas venerables de estos viejos - niños, incapaces de suponer dobleces y traiciones en sus semejantes-, está siem-

${ }^{11}$ Carlos Gagini, Cuentos y otras prosas (San José: Lehmann, 1971), p. 70.

${ }_{12}$ Véase Rodrigo Solera, «Jenaro Cardona, cumbre del realismo naturalista en la novela de Costa Rica», en Revista de Estudios Hispánicos, University of Alabama, vol. V, núm. 3, octubre 1971, p. 377. 
pre abierta la garra del engaño, y levantado el alfanje del beduino civilizado, pronto a entrar a saco sobre un hogar feliz siempre que éste ofrezca incentivo a la rapiña y a la expoliación ${ }^{13}$.

Julián, su hijo, hereda de don Clemente el legado patriarcal de «honradez y lealtad», equilibrado con «un juicio admirable y un criterio poco común». Su «austeridad» y sencillez lo inmunizan, por un lado, contra las tentaciones mercantilistas - a las que es tan proclive su hermana $\mathrm{Ma}^{-}$ tilde-; pero, por otro lado, lo hacen fácilmente vulnerable -como su padre- a las intrigas y la hipocresía de los «beduinos civilizados»: es decir, los nuevos ricos como don Eduardo Cartín o don Agapito Mendoza, que esconden bajo su «fama de hombre honrado» la «bellaquería» y la «expoliación» sobre las que han edificado su «fortunita» (p. 123).

E1 tercer miembro de la familia Ayala y principal protagonista de la novela, Matilde, es, según el narrador, «el reverso de Julián» (p. 27). La contradicción entre su posición elevada y sus exiguos recursos económicos convierte a Matilde, a pesar de su formación patriarcal, en presa vulnerable a los «valores de cambio» burgueses:

La pobre criatura, en su desmedida afición al lujo y a las cosas grandes, no tenía en su cerebro de pájaro más idea que la de ostentar, la de deslumbrar, y no pensaba que cuando no hay oro que refleje su brillo sobre la persona, todo aquel lujo, todo aquel aparato no es otra cosa que un oropel que cubre las miserias más vergonzosas y exhibe a las personas de la manera más ridícula. Pero Matilde no pensaba en esto; por brillar una noche en un baile, y verse nombrada por cualquiera pelagatos de imprenta en una gacetilla cursi y trasnochada, obligaba a su padre a las mayores privaciones y sacrificios (pp. 30-31).

La segunda trama, que se subordina a la primera, recoge un tema frecuente en los inicios de la literatura costarricense, que Claudio González Rucavado ya había elegido en 1901 para su novela El hijo de un gamonal. Es el tema del «gamonal», del campesino enriquecido, al que el dinero le permite aspirar a competir con la oligarquía urbana. Esta segunda trama -encarnada en la familia Astorga y la figura del joven Mario, alias «Tri1lito»- expresa el tema de la penetración de los valores mercantiles en el modo de vida rural. Trillito, que se traslada a San José para competir por una posición social acorde con el flamante poder económico de sus padres, se debate entre sus débiles escrúpulos patriarcales — ligados al

${ }^{13}$ Jenaro Cardona, El primo (San José: Ed. Costa Rica, 1980), p. 28. En adelante, las citas siguientes se harán según esta edición, indicando entre paréntesis el número de página correspondiente. 
campo y la vida familiar-y sus poderosas ambiciones sociales —ligadas a la vida urbana.

Astorga viene a ser así una especie de copia al revés de Matilde Ayala. El rasgo estructural que une las dos tramas es la posición socioeconómica intermedia de los dos protagonistas: Matilde, con posición social pero sin el dinero necesario para mantenerla; Mario Astorga, sin posición social pero con el dinero necesario para pretender comprarla.

De aquí el papel central del dinero en la novela: él es mediador entre los deseos de los protagonistas y la realidad; sólo el dinero otorga la posibilidad de dar apariencia real a las ambiciones potenciales de los personajes. De aquí que el dinero se convierta para los protagonistas - consciente o inconscientemente- en una necesidad indeclinable y su poder en una tentación irresistible. La necesidad de dinero - mediador entre la ambición y el éxito- hace que los personajes conviertan en valores de cambio - mercancías que pueden venderse para satisfacer sus ansias de placer, de lujo o de lucro- sus principios, sus sentimientos o su conciencia.

En este ambiente social urbano, propenso a la corrupción y la degradación, aparece Beltrán Urdaneta, el primo extranjero de Matilde, cosmopolita, rico, egoísta y libertino:

Beltrán era un gran egoísta en el más alto sentido metafísico. Todas las ventajas, todos los atributos de que disponía, los empleaba única y exclusivamente en proporcionarse el placer a montones, para devorarlo luego con una avidez asombrosa...; y sabía cuánto pueden una buena figura, pocos años y muchos pesos (p. 69).

El fermento exótico que viene a provocar en El primo la descomposición de las costumbres y valores patriarcales es la conjunción en la figura de Beltrán Urdaneta del dinero y el libertinaje, unidos además a la fascinación de la oligarquía criolla por el brillo extranjero. No es difícil establecer aquí un irónico paralelo entre El primo e Hijas del campo: el lujo y la riqueza de Beltrán conquistan a la aldeana «aristocracia» criolla, como el lujo y el dinero de Melito conquistaban a las aldeanas «hijas del campo». En ambos casos, el libertinaje y la impunidad moral son producto del traslado, al campo de las relaciones humanas, de las leyes mercantiles y de la sustitución de "valores de uso» patriarcales por valores de cambio: la virginidad, la honra, el amor o el matrimonio se tornan mercancías, que se compran o se venden cuando la oferta es atractiva o la necesidad apremiante.

Toda la estructura de la novela tiende a señalar, tanto en las costumbres sociales como en el comportamiento de los personajes, ese desgarra- 
miento entre los viejos valores patriarcales y los nuevos valores de cambio burgueses. Las referencias a las costumbres josefinas son indicio de un mundo en el que el prurito por salvaguardar apariencias y pretensiones sociales artificiales y ficticias lleva a los personajes a actuar de manera a veces ridícula, a veces trágica, en contra de sus posibilidades y de sus auténticas necesidades. Por otra parte, los personajes de don Eduardo Cartín y la familia Mendoza — don Agapito y su esposa Valentina- aparecían ya desde los primeros capítulos, y antes del arribo de Urdaneta, como el equivalente criollo de lo que con más refinamiento y elegancia representa el primo Beltrán: el individualismo burgués, el culto al dinero y el libertinaje. Para estos personajes, las relaciones humanas, el matrimonio o los negocios se conciben como una empresa privada, cuyo valor se mide por la cantidad de dinero o la satisfacción personal que aportan.

La presencia del extranjero cosmopolita, rico y libertino, no hace más que enardecer los desgarramientos y contradicciones de la incipiente sociedad burguesa josefina; el primo Beltrán sólo actúa como catalizador que precipita un proceso cuyos elementos estaban quizás latentes y agazapados, pero preparados y activos en el ambiente social de San José.

De aquí que el poder seductor del primo sea el núcleo alrededor del cual giran y se definen los valores y actitudes de los demás personajes. Las posiciones de los personajes pueden resumirse en el siguiente esquema:

Valores patriarcales

Diego

Familia Ayala

Familia Astorga
Oscilantes entre ambos Matilde Ayala Mario Astorga

\section{Valores mercantiles}

Beltrán Urdaneta

Burgueses criollos: Eduardo Cartín, Agapito y Valentina de Mendoza

En el extremo opuesto a Urdaneta, Cartín y los Mendoza, representantes de la sedición mercantilista, se encuentra Diego, el más cabal y auténtico representante de los valores y mitos del liberalismo patriarcal costarricense; los sueños de Diego coinciden plenamente con sus añejas convenciones y ritos doméstico-patriarcales:

E1 necesitaba casarse, formar su hogar, procrear su familia; no pasar por el mundo como un sonámbulo ajeno a los goces del amor, que brilla en medio de un hogar honrado y feliz... El quería tener el estímulo santo del trabajo que santifica la vida y compartir el fruto de sus fatigas con una familia suya, propia, que fuera carne de su carne... Y sobre tanta dicha, sobre tanta ventura, el escudo de un nombre honrado y la consideración social (p. 181). 
Como novio oficial de Matilde, Diego representa para ésta la concepción tradicional - patriarcal- del matrimonio, en oposición a la tentación y las acechanzas de los burgueses libertinos criollos y, más tarde, del primo extranjero.

La posición socioeconómica intermedia de Matilde provocaba, sin embargo, desde un principio, ciertas dudas y oscilaciones, ciertos «sentimientos encontrados», entre sus principios patriarcales - la relativa seguridad que le ofrece el matrimonio y su «amor» por Diego- y la oscura atracción de los placeres burgueses: la «secreta voluptuosidad de lo prohibido», que lleva «al alma de Matilde una especie de ateísmo en su religión de mujer» (p. 66; subrayado en el original).

Eduardo Cartín y Valentina, los representantes criollos del mercantilismo burgués, actúan como instigadores preliminares —antes de la aparición del primo- de los incipientes brotes mercantilistas en el ánimo de Matilde, y cumplen en este sentido el papel de coadyuvantes de la posterior seducción del primo y de opositores a los proyectos matrimoniales de Diego.

Don Eduardo Cartín había intentado infructuosamente, antes del arribo de Beltrán, "comprar» un matrimonio con Matilde, valiéndose de su ingente poder económico y de las penurias de los Ayala. Por otra parte, los consejos de Valentina a Matilde en el capítulo III tendían también también a debilitar el ya titubeante «amor» de Matílde y su compromiso con Diego; al mismo tiempo sembraban en el ánimo oscilante de Matilde las semillas mercantilistas, que la presencia seductora del primo cosmopolita, millonario y libertino hará germinar más tarde.

_... iAh picarilla, con que tienes un primo millonario!... Créeme, estás de que te felicite... ¿Beltrán es soltero? Sí, pues está todo hecho; ¿qué les impide a ustedes que se gusten, se quieran... y...

- iPero es que te haces la ignorante? ¿No sabés que tengo mi novio y que estoy comprometida?... El talento se abre camino siempre, y perseverando, con trabajo y economía se llega al fin deseado.

-Pues hija, te equivocas medio a medio. ¿No has oído decir que el talento es un estorbo para hacer dinero? Ahí tienes a mi marido... ¡buen ejemplo! Además, casarte para trabajar, para economizar y para enflaquecer es sencillamente una estupidez (pp. 40-41; subrayado en el original).

Matilde, sin embargo, rechaza las asechanzas y proposiciones de los burgueses criollos, para conservar su fidelidad algo titubeante al compromiso con Diego y a los principios patriarcales: 
-Nunca - contestó Matilde con voz firme y por hacer ostentación de un sentimiento que es dudoso que experimentara-: seré fiel a mi compromiso; para venderme ya lo habría hecho cuando el señor Cartín me mostró cierta inclinación que... tal vez aún me profese... y no puedes negarme que es rico... Soy de las que creen que el amor verdadero, que sí existe, aunque lo niegues, es lo que más dignifica y levanta a la criatura y debe ser la única cadena capaz de unir dos seres...

-Al poste de la miseria -interrumpió Valentina (pp. 41-42).

Pero los mercaderes criollos no tienen el poder de seducción que tiene el millonario extranjero. Beltrán inicia la seducción de Matilde con el regalo de un collar de perlas:

Matilde quedó deslumbrada al ver la joya; tuvo un momento de arrobamiento cuando contempló el centelleo de los diamantes, entre el blanco mate de las perlas (...). No miró más ni se dio cuenta de nada; sintió que unas manos le ceñían al cuello aquella alhaja que parecía que la quemaba... Sintió sobre su boca la caricia del bigote de Beltrán, quien la besaba furiosamente, y que la ahogaba. Tuvo una especie de desmayo... Urdaneta la retenía entre sus brazos; mas de pronto, con la enorme fuerza de una mujer débil que se defiende, se desprendió de Beltrán, le miró espantada, casi loca, y con paso acelerado huyó de la sala... (pp. 108-109).

E1 lujo, la elegancia y la fortuna del primo Beltrán terminan por seducir a Matilde, y su habilidad para ocultar con un discurso y una apariencia patriarcales sus prácticas libertino-burguesas terminan por ganarse la simpatía de don Clemente y Julián. Tras seducir y embarazar a Matilde, sin que lleguen a sospecharlo sus parientes, el primo abandona precipitadamente Costa Rica, pretextando una gravedad de su padre. Antes de partir envía a don Clemente una cariñosa misiva y una «pequeñez»: un cheque por valor de 3.600 pesos.

Cuando don Clemente terminó la lectura, corrían las lágrimas de sus ojos...

- ¿Has visto un muchacho como éste? ¡Ah!, Beltrán vale lo que pesa... icorazón de oro! Quiera Dios que encuentre vivo a don Esteban, y que la dicha lo acompañe (p. 186).

De manera paralela a las dudas y oscilaciones de Matilde, el narrador desarrolla la segunda trama. También Trillito se debate entre sus tímidos principios patriarcales, ligados a la vida familiar y a su formación campesina, y sus turbulentas ambiciones burguesas, ligadas a la vida y las tentaciones urbanas. 
Al aparecer en escena, la vida josefina ya ha borrado casi completamente del alma de Astorga los últimos escrúpulos patriarcales campesinos. Pero más tarde, cuando vuelve a su pueblo natal y al seno familiar (en los capítulos XVIII, XIX y XX), los recuerdos y el contacto renovado con su familia despiertan ciertos brotes de nostalgia y hacen renacer sus dormidos escrúpulos patriarcales. Finalmente, cuando en el capítulo XX su padre lo coloca entre la espada y la pared, entre el campo o la ciudad, la tradición patriarcal o el libertinaje burgués, Mario no duda en escoger:

¿Qué haría? Renunciar a la vida de San José después de haber saboreado sus goces $i y$ los amigos, y los bailes, y sus grandes proyectos de hacerse periodista... y la diputación que ambicionaba, y la vida de esplendor con que soñaba? ¿Oh, no! ¿Quedarse allí, volverse un campesino, encerrar todos sus sueños y aspiraciones en el estrecho círculo de aquel pueblecillo? Jamás, de ninguna manera... (pp. 166-167).

El mismo poder de atracción, seducción y convencimiento que ejerce el millonario extranjero sobre Matilde y la familia Ayala se aplica también a los ya raídos principios patriarcales de Mario Astorga. Para remediar la «deshonra» de la prima, Beltrán propone a Trillito una atractiva transacción erótico-mercantil: el matrimonio con Matilde. Astorga «regatea» en claros términos sociocomerciales las ventajas y dificultades del «contrato»:

-... Nuestra sociedad es complaciente, todo lo olvida, pero siempre que el asunto se rodee de cierto brillo... porque no me negará usted que algunas faltas llegan a cubrirse bajo las sedas y las joyas, mientras que otras estarán presentes, siempre vivas, si no tienen en su disculpa más que las lágrimas del arrepentimiento por sinceras que sean... iqué quiere usted!, jasí es el mundo! (p. 188).

Finalmente Trillito se vende, cuando Beltrán —quien reconoce que Astorga "ha hablado... como un filósofo» (p. 188) - le ofrece una cantidad de dinero lo bastante atractiva.

Así como las actitudes ante el amor y el matrimonio, también las prácticas que rigen los negocios plantean un choque y un enfrentamiento entre la concepción patriarcal de Diego - fundada en la honradez, la lealtad y la nobleza- y el mercantilismo burgués de Cartín y los Mendoza, para los que el valor de los actos y los principios se determina según la cantidad de dinero o la satisfacción personal que produzcan. El enfrentamiento entre ambas posiciones se hace evidente con el affaire de las huérfanas Montes, de las que Cartín es al mismo tiempo tutor y expoliador, con la complicidad de Agapito Mendoza, y de las que Diego se convierte en abnegado defensor. 
Al igual que Beltrán, también Cartín logra engañar fácilmente con su doble comportamiento -un lenguaje y una apariencia patriarcales que disimulan y encubren prácticas burguesas- la honrada sencillez de los Ayala, algo predispuestos ya a aceptar el engaño por la «gratitud» que don Eduardo se ha ganado con sus oportunos «servicios» a la familia. Don Eduardo

Inventó, tergiversó hechos, citó detalles desconocidos por completo para todos, y con tal arte y maestría, que logró llevar al ánimo de don Clemente y de Julián un sentimiento de repulsión hacia Diego (p. 125).

Los áltimos capítulos de la novela reúnen los diversos temas de las dos tramas, llevan a su desenlace los conflictos entre los personajes y extraen las consecuencias finales del conflicto estructural entre los valores y prácticas del viejo liberalismo patriarcal y el nuevo mercantilismo burgués aliado a la «secreta voluptuosidad» del millonario extranjero.

El poder seductor del millonario extranjero disuelve irremisiblemente los últimos escrúpulos patriarcales y provoca la degradación final de los protagonistas de las dos tramas: Matilde es seducida y deshonrada por el primo; Trillito es sobornado y comprado por Beltrán para que intente reparar la deshonra. Los otros miembros de la familia Ayala —el declinante nido de hidalgos patriarcal- son también insensiblemente burlados y conquistados por la ambigüedad engañosa de los valores de cambio que manejan los nuevos mercaderes, Beltrán o Cartín. Don Clemente y Julián son incapaces de reconocer o enfrentar las nuevas prácticas sediciosas, que se encubren tras el respeto a los ritos, costumbres y tradiciones establecidos.

Por otra parte, Diego, el más lúcido y consecuente representante de los valores patriarcales, es incapaz — con sus prácticas basadas en la franqueza, la rectitud y la honradez- de defender a Matilde del asedio y la atracción del primo; y de defenderse a sí mismo contra las tergiversaciones insidiosas de Cartín, quien predispone en su contra a los mismos que, por su manera de ser y de pensar, debían constituirse más bien en sus aliados patriarcales.

El final de la novela es símbolo expreso de la impotencia del viejo liberalismo patriarcal para enfrentar las prácticas sediciosas del nuevo mercantilismo capitalista. Don Eduardo Cartín confunde a Julián, haciendo aparecer a Diego -rival de don Eduardo en el amor y en los negocios- como autor de Ia deshonra de Matilde, y provoca así la muerte del honrado Diego a manos del ingenuo Julián. La novela termina entonces con una imagen simbólica de la autodestrucción del elemento patriarcal, víctima impotente de la ambigua atracción del extranjero, de las prácticas engañosas de Cartín y de sus propias contradicciones internas; todo ello 
provoca la destrucción física de Diego, ejecutada por el inadvertido Julián, y el desmoronamento completo del decadente nido patriarcal de los Ayala.

La visión del mundo que se expresa en la novela El primo no deja de mostrar una cierta contradicción entre los hechos narrados y la interpretación ideológica de esos hechos que el autor sugiere. Desde el punto de vista ideológico, Cardona parece aceptar como válidos e identificarse con los valores patriarcales que Diego y los Ayala encarnan y deîienden en la novela. Pero, por otra parte, la obra expresa tácitamente la caducidad histórica de esos valores, al demostrar la impotencia de los personajes que los defienden para enfrentar con ellos los nuevos valores burgueses. Los valores mercantilistas, de una u otra forma, terminan por seducir, contaminar o corromper a los miembros de la carcomida sociedad semipatriarcal costarricense.

De los análisis anteriores podemos concluir que tanto Hijas del campo como El primo expresan una concepción literaria de la realidad totalmente opuesta a la imagen idealizada de un mundo armonioso y cordial, regido por costumbres y tradiciones patriarcales, de sus contemporáneos «costumbristas». La visión de una realidad social degradada, ambivalente y contradictoria que ofrecen estas dos novelas refleja desde diversos puntos de vista el fenómeno de sustitución del viejo liberalismo patriarcal costarricense por el incipiente liberalismo burgués, junto con el crecimiento de las relaciones mercantiles y la desposesión del campesino.

La posición ideológica de los autores ante los fenómenos descritos difiere, sin embargo, sustancialmente. Ambos coinciden en la crítica a las consecuencias disociadoras y deshumanizantes que conlleva el desarrollo de las relaciones mercantiles. Pero Cardona enfoca este proceso desde el punto de vista de las clases medias - la oligarquía empobrecida o los gamonales enriquecidos-y sólo le preocupan las consecuencias desmoralizantes que tiene ese proceso sobre la oligarquía costarricense. El mercantilismo y la hipocresía de la nueva sociedad burguesa josefina aparece en su obra como producto del abandono o la transgresión, por parte de las capas sociales intermedias, de los preceptos socio-morales del viejo liberalismo patriarcal. Cardona no pone en duda, por lo tanto, la validez de los principios socio-morales sobre los que se edificó el viejo liberalismo patriarcal, ni el derecho de la oligarquía a disfrutar de la sujeción del campesino: la preocupación por la injusticia social está totalmente ausente de su obra. 
García Monge, en cambio, enfoca ese mismo proceso desde otro punto de vista: el del campesino pobre, desamparado y desposeído. La descomposición socio-moral que conlleva el crecimiento de las relaciones mercantiles y el desarraigo de la vida urbana constituye en la obra de García Monge no sólo - como en Cardona - una protesta contra la desmoralización de la oligarquía, sino también - y sobre todo - una protesta contra un mundo deforme e inhumano, basado en relaciones sociales que tienden a perpetuar los privilegios oligárquicos sobre la desposesión y la miseria de los campesinos. En este sentido, su obra se opone tanto a la ideología del viejo liberalismo paternalista — con su apreciación nostálgica de las relaciones patriarcales - como a la ideología del liberalismo burgués, para el que la explotación, la desposesión y el desamparo son el precio ineludible del «progreso» económico. Desde un punto de vista ideológico, la obra de García Monge se emparenta más bien con las ideas «ácratas» o «anarquistas» de los jóvenes radicales costarricenses de las primeras décadas del siglo, que fundaron, en 1912, el Centro de Estudios Sociales «Germinal», y que constituyen en la historia de Costa Rica el primer intento por oponer una ideología de corte socialista al «liberalismo» y al «clericalismo» decimonónicos. 
